\title{
ENABLING WELL-BEING AND EPISTEMOLOGICAL ACCESS THROUGH AN AUTHENTIC ASSESSMENT INTERVENTION: A CASE STUDY OF A HIGHER EDUCATION PROGRAMME
}

\author{
R. Maniram \\ Department Hospitality and Tourism \\ Durban University of Technology \\ Durban, South Africa
}

\section{S. M. Maistry}

School of Education

University of KwaZulu-Natal

Durban, South Africa

e-mail: maistrys@ukzn.ac.za

\section{ABSTRACT}

The South African higher education context presents with multiple challenges. One such challenge is the ability of institutions to effectively respond to the academic needs of the students that enter university. While there are several instances of programme development that attempt to address the academic well-being of students, the pedagogic strategies of many programmes are often not well grounded in sound educational theory. In this article, we report on a study that examined student experiences of an academic programme that is informed by the concepts "authentic assessment" and "epistemological access". The methodological approach was guided by the tenets of Interactive Qualitative Analysis (IQA), (Northcutt and McCoy 2004). A purposive sample of Hospitality Financial Management students at a university of technology was drawn. Key data generation instruments included individual and focus group interviews, online chats and online reflective journals. One compelling finding which we take up in this article is the power of student collaboration as a powerful enabling mechanism for epistemic access.

Keywords: authentic assessment, epistemic access, collaboration

\section{INTRODUCTION}

It is indeed laudable that the South African higher education context has changed significantly in the post-apartheid era. Of particular note is the dramatic increase in student enrolments in undergraduate programmes across almost all universities (Hornsby and Osman 2014, 712-714). In recent years, student activism has further contributed to advancing the project of increasing access to higher education through nationwide student mass action. The "Fees Must Fall" campaign, an outcome of the "Rhodes Must Fall" movement, has in no uncertain terms played 
a distinct role in ensuring that indigent students who qualify as a result of meeting the state's protocols for qualifying for financial assistance, can in fact access higher education (Lange 2017, 34-38). In essence then, the economic well-being of such students, is to an extent a matter that is beginning to receive due consideration. While this is certainly a positive development in the history of South Africa's higher education project, there is a definite need for this euphoric sentiment to be tempered with a high level of caution.

This caution is certainly not without basis. While the political will to provide access by partially removing financial barriers to university education is a positive step forward; access to the "goods" of the university cannot be overlooked. In this article we draw on the seminal work of Morrow $(2009,77)$ to argue that physical access alone is not sufficient, as increased enrolments have historically not translated into equivalent student throughput (Scott 2009, 3235). Within the learning spaces of a university, students are challenged to negotiate and access disciplinary knowledge. This access to disciplinary knowledge and the ways of knowing within a discipline was coined by Morrow $(2009,36-38)$ as "epistemological access". This article reports on a study that set out to explore the extent to which an Authentic Learning strategy might enable epistemological access in a taught Hospitality Financial Management course (HSFM101) at a university of technology, a programme that is classified as "at risk" at this institution.

South African higher education institutions have a particularly dismal track record and poor performing system, that mirrors discrepancies and other social and economic biases (Scott, Yeld and Hendry 2007, 9-11; CHE 2013, 14-16). For example, access, success and completion rates in higher education perpetuates racial skewness in that White and Indian success rates show more than half of that of African success rates. Furthermore, the disproportions in access and success shows less than 5 per cent of African and coloured youth are actually succeeding in any form of higher education (CHE 2013). Student's performance in South African higher education flags high levels of failure and dropout rates (Van Zyl 2013, 4-6; CHE 2013, 14 16). That most poor students who emerge from disadvantaged contexts and dysfunctional schools (Spaull 2015, 34-36) have gaps in their competence sets, is indeed a moot point. That the schooling system has rendered high school graduates with different levels of (under)preparedness for success in higher education is also a moot point. That the country's fragile schooling system will remedy itself in the near future is also highly debateable. One might arguably conclude that the status quo is not likely to alter dramatically in the foreseeable future. Note, that we want to categorically declare that we are not arguing for linear causal relationships between increased access (to the nation's poorer students) and (their) subsequent "failure" once admitted. If anything, we want to argue that it is the (higher education) system 
that has in fact "failed" these so-called "non-traditional" students. While some institutions, their academic departments and programmes have embraced the notion of responding to the new "calibre" of students that now enter university, many institutions have either apathetically wished that the problem would disappear, while some have reacted with "knee-jerk" interventions, often not well grounded in educational literature/theory.

In this article, we report on a study of a theoretically informed intervention designed to enhance the academic well-being of students. We focus on students' disciplinary access to a unique, largely unfamiliar disciplinary context, namely, the disciplinary field of hospitality financial management. Hospitality Financial Management is a module within the Programme Hospitality Management that has historically been well-subscribed to at universities of technology. However, it has notoriously been plagued by high failure rates, and remains a highrisk disciplinary subject (Goh and Scerri 2016, 85-87). While there are several complex reasons for student difficulty with this subject area, one compelling factor is that in the main, students who signed up for the programme have little or no lived experience of the world of financial management and the world of tourism and hospitality in particular. The clarity of the specificities of what this actually means stems from an understanding of and an acknowledgement that the goods and services of the hospitality and tourism industry have a very distinct target market that is synonymous to that of the middle class. The world of domestic and international travel for leisure, hotel vacations, hotel facilities and accommodation, banqueting etc. is usually outside the domain of the poor. In fact the predominant experience of a large proportion of students at the institution under study is that many have never had the affordance of staying at a paid holiday accommodation, visited a hotel or seen or even ate at a fine dining restaurant. The Hospitality curriculum may include taken for granted "contextual" knowledge of the Hospitality field and might be overlooked in teaching and learning (CHE 2013, 18).

As such, the content/disciplinary knowledge of this disciplinary field is outside the lived experience of the students who study to build a career in this industry. There is thus a dearth in our understanding of how such students access this disciplinary field and the dissonances they might encounter when having to engage with the disciplinary discourse and theory. In this article, we present the findings of a study that sought to explore the learning experiences of such students, students whose previous exposure to abstract theory of a subject field that was "foreign" to their life experience.

On the basis of historical and tacit knowledge of what the barriers to learning might be, we turned to the field of established research on authentic assessment to draw insights for a pedagogical intervention (Ashford-Rowe, Herrington and Brown 2014, 205-207). This article 
thus reports on a study that set out to explore how authentic assessment can enable epistemological access in a Hospitality Financial Management programme at a university of technology. The study was conducted in the Faculty of Management Sciences at the DUT, located in the Hotel School in the Department of Hospitality and Tourism. The module, Hospitality Financial Management 1 (HSFM101) was the focus of the study. Data was generated in 2016 and 2017. The average size of the Hospitality Financial Management 1 class was 150 students from diverse cultural backgrounds and social classes.

\section{AN OUTLINE OF THE AUTHENTIC ASSESSMENT (AA) PROJECT: HSFM101: "MY CULINARY HERITAGE DAY PRODUCT"}

The key intention of the AA task was to create an authentic context that students could relate to. In planning the task, careful attention was paid to mapping the identified theoretical knowledge (concepts and principles) as well as skills that would be targeted for mastery. These identified knowledges would then be integrated into the multiple dimensions/stages of the project. Given that almost all students in the programme, may not have been exposed to any form of first-hand experience with both the concepts and principles as well as their application to a real context, this particular AA project was crucial in creating the context for learning.

At the start of the semester, students were placed in groups of 6 and were assigned the main task of developing a food menu as well as the costing of the menu items which they would eventually market and sell to the public. Heritage Day in SA was selected as the theme that would guide the menu. For this they had to conduct the necessary research on a variety of indigenous food consumed by South Africans.

Students were given 6 weeks to prepare for the big entrepreneurial day. A series of financial subtasks was set with specified timelines as applicable in any business context.

Over the six week period, students were exposed to key theory and guidance for their application throughout the project. This included basic HSFM101 concepts and principles and preparation for the ultimate preparation of basic business financial statements.

\section{A KEY CONCEPTUAL POINT OF DEPARTURE NAMELY, EPISTEMOLOGICAL ACCESS (EA) AND AUTHENTIC ASSESSMENT (AA)}

In an intriguing article entitled "Every picture tells a story: Epistemological access and knowledge", Muller (2014) traces the origin and evolution of the concept "epistemological access", drawing attention to how it has returned to vogue and how inadvertent slippage in its appropriation might unwittingly translate into narrow applications. He argues for the need to re-centre knowledge as opposed to pre-occupations entirely with practice outside of knowledge. 
He maintains that a nexus of "knowledge of theory" and "knowledge of practice" might be useful suggesting that both "know that" and "know how" have resonance. He argues that all knowledges have procedural knowledge as well as theoretical knowledge (Muller 2014, 263). Certain vocational fields might well have historically focused on practice at the expense of theory.

Over the past few decades the concept of EA has gained traction in the transformation discourse and debates (Vorster and Quinn 2017, 38-39). Such debates centre on EA and the pedagogies that promote it (Boughey 2005; Kotta 2006; Mgqwashu 2007; Ferreira and Mendelowitz 2009; Maphosa et al. 2014; Nkonki and Ntlabathi 2014; Arbee, Hugo and Thomson 2014; Liccardo, Botsis and Dominguez-Whitehead 2015; Layton and Mckenna 2016; Antia and Dyers 2016; Mollett and Cameron 2016; Ellery 2017; Rusznyak et al. 2017).

The concept of EA was coined by Wally Morrow (2009, 77-78) during the 1980s and should be understood within the broader concept of access which has its own political and social agenda within South African HE. Morrow's argument more than two decades ago still has currency in the contemporary South African higher education context. He argued then, that gaining physical access to the goods of the university, does not always guarantee academic success, emphasising that "learning how to become a successful participant in an academic practice" (Morrow 2009, 6) is key. It is unlikely that a student with serious conceptual knowledge gaps would acquire epistemological access on her own. Higher education institutions thus need to embrace academic practices that facilitate EA (Boughey and Niven 2012, 641-643), which might necessitate a re-examination of current practices with a view to responding to the lived experiences of the students they enrol; enabling students to acquire ways of knowing that promote academic success (Morrow 2009, 75-77). Thus, academics need to embrace pedagogical practices that induct students in the grammar, procedures, rules and logic of the specialist discipline; the discourse of the discipline. Morrow $(2009,37-39)$ notes, that, EA promotes alignment between institutional values and students' personal epistemological attributes. It enables a student to confidently and independently access the ways of doing and thinking within a particular discipline (Morrow 2009, 38). It may also address how new entrants to the system are confronted with epistemic barricades, that may be imposed or self-imposed (Antia and Dyers 2016, 526-527).

Gamede $(2005,58)$ argues that Morrow's concept of EA, "rules out the existence of a hidden curriculum that favours some and excludes others". Gamede $(2005,20-21)$ and Furlong (2009, 343-346), point to the need to consider the political and social dimensions of access to education. They add that Morrow's conceptualisation does not pay sufficient attention to disadvantaged students and the lack of support mechanisms to enable them to improve their 
chances of academic success. Muller $(2014,258)$ and Heleta $(2016,1-3)$ concur that EA is about promoting a social and epistemic justice agenda. Similarly, Waglay $(2013,2-4)$ argues that whilst formal access should be driven by the politics of difference; EA should be driven by the politics of equal dignity. The debate on EA thus extends to who is responsible for ensuing it occurs. Lotz-Sisitka (2009, 57-59) and Slonimsky (2006, 37-39) posit that HEIs hold this responsibility.

In the SA higher education context, many students are unfamiliar with the dominant culture and discourse in HE (Boughey and McKenna 2016, 4-6; Snowball and McKenna 2017, 605-607). For example, black working class students struggle to engage with complex abstract concepts in a language other than their home language; this is presented as the "language problem" (Boughey and McKenna 2016, 2-4).

It is imperative that HEIs acknowledge and address diversity and difference through the enactment of transformative pedagogies; that providing students with learning-context access enables them to achieve EA (Ellery 2017, 915-916). Acquiring EA means that students are able to acquire the appropriate disciplinary identity and participate effectively in the discipline's Students from working class homes or first generation students may encounter difficulties in grasping academic Discourses (Boughey and Mckenna 2016, 2-7) due to their limited exposure to them. Consequently, power and class determine a student's "ways of being". It is for this reason that Vorster and Quinn $(2017,38-39)$ argue for the need to facilitate ontological as well as epistemological access.

Accessing the discourse of the discipline within a Hospitality Financial Management context would include the values, attitudes, habits of mind, beliefs, problem solving abilities, drawing up of financial reports and ways of communication pertinent to the Hospitality manager. Jacobs $(2007,59-65)$ maintains that the role of disciplinary lecturers (considered as the "insider" to the discipline) is to facilitate students' (the "outsiders" of the discipline) access to the discourse of a discipline through participation in that particular discourse community. Likewise, acquiring disciplinary access means being recognised within a discourse community through successfully using its language.

However, academics (considered as the discipline experts) may be so immersed in their disciplinary field that they find it difficult to articulate or enable access to knowledge to their students (Jacobs 2007, 59-61). This prevents students from learning and understanding discipline content. Furthermore, EA requires that students grasp disciplinary language which is closely aligned to the acquisition of disciplinary knowledge.

In order to access the disciplinary knowledge of Hospitality Financial Management, specific knowledge and dispositions need to be legitimated. International literature suggests, 
that students from certain backgrounds may be culturally and socially privileged due to the schools that they attended (Tierney and Hagedorn 2002, 1-3; Strayhorn 2010, 308-310). "Cultural capital", refers to the high-status linguistic and cultural competencies that students inherit from their parents and other "cultural brokers" such as siblings and peers, and “institutional agents”, such as schools (Stanton-Salazar 1997, 2-6). Similarly, some studies have found that the type and amount of capital a student brings to university is a powerful predictor of academic success (e.g., Warburton, Bugarin and Nunez 2001, 6-9; Egalite 2016, $2-5)$. The challenge then is to reconceptualise the pedagogic event which necessarily means a re-examination of teaching and assessment strategies. Authentic assessment (AA) offers a theoretically informed medium to give effect to this imperative.

There has recently been a shift to the alignment of assessment tasks through emerging technologies and authentic learning environments (Ashford-Rowe, Herrington and Brown 2014, 205-206; James and Cassidy 2018, 402-403). In contrast to traditional instructional settings, an authentic learning environment exposes students to first hand, real-life experiences, (Mingo 2013, 11-15). The student is more likely to access knowledge in such a setting, as learning is not separated from its context (Herrington and Oliver 2000, 23-26; Mingo 2013, 12-16), a strategy that has much resonance for hospitality studies. The assessment tasks should teach students about the real world of hospitality. The idea is that students might be able to demonstrate learning by integrating what they know (epistemology) and are able to deal with who they are becoming (ontology) as they engage new learning in authentic contexts. Tasks thus have to be designed in accordance with real-world activities in a realistic setting. Furthermore, such tasks ought to be attached to real-life values in which their attributes emphasise knowledge and are aligned to an epistemological focus (Vu and Alba 2014, 779).

\section{THE AUTHENTIC LEARNING PROJECT: A BRIEF DESCRIPTION}

At the first HSFM101 lecture, all students were provided with a learner study guide that included the authentic learning project as a formative assessment, details on this project, the sub tasks needed to be undertaken and how it would contribute to their year mark. At the start of the semester the selected participants were further orientated on the research outcomes and their role in the study. The sample group was invited to be part of the eLearning experience and all students (research participants and non-participants) were inducted on how to access and use the online software - Blackboard (BB) as a learning tool. For the purpose of the study the participants were required to update their learning experiences in Hospitality Financial Management on a daily basis using the online journal. Students were also inducted on how to access, upload and download BB online activities. Students were constantly reminded on the 
upkeep of their online journals.

In addition to seeking to understand what enabled or constrained students' EA in HSFM101 in an authentic learning encounter, I also used this research opportunity to provide additional tutorial support to the sample (over and above the regular tutorials they attended).

\section{A BRIEF METHODOLOGICAL NOTE ...}

This qualitative study, aligned to the social constructivist paradigm attempted to study the meaning of participant's lives within certain contextual conditions, with a particular focus on exploring the extent to which epistemological access might be enabled trough an authentic assessment strategy (Yin 2011, 308). In a constructivist approach, the meaning of experiences and events is constructed by individuals; they therefore construct the realities in which they participate (Charmaz 2006, 12-16). Interactive Qualitative Analysis developed by Northcutt and McCoy (2004) was used to understand how students acquire EA within HSFM101. IQA has not been widely used in the South African context except for a few limited studies (Tabane 2010, 50-51; Mampane and Bouwer 2011, 115-119; Human-Vogel 2006, 613-616; HumanVogel and Mahlangu 2009, 309-312). Note that IQA rigorously aligns its processes to the tenets of social constructivism, as knowledge is constructed through social participation. An intrinsic characteristic of an IQA study is that it has its own rigour. Concomitantly, it presents a transparent, systematic audit trail that accounts for a rigorous and reliable process.

The data were gathered by means of focus groups, semi-structured, open-ended interviews, and through participants' online reflective journals. A purposive sampling technique was adopted as it considers the choice of participants that are closest to phenomenon under study and those that are willing to share their experiences and knowledge (Etikan, Musa and Alkassim 2016, 2-3). In purposive sampling, participants are selected according to key criteria to ensure that they are relevant to the subject matter. Although purposive selection involves deliberate choices, bias should not be reflected in the selection a caution that we gave due attention to (Sharma 2017, 751-752). A sample of 20 participants was selected, participating in the tutorial group throughout the semester as well as the focus group for the IQA to be implemented towards the end of the module. We used the focus groups to develop deeper insights into participants' experiences of learning. It also enabled participants to engage positively with the research process by generating rich, in-depth data based on group interaction (Rabiee 2004, 655-657).

In applying the IQA protocol, several key findings emerged. In this article, we focus on arguably the most compelling finding that spoke to how epistemic access was most convincingly facilitated. Contrary to the literature which pointed to the pedagogue as the 
significant agent in enabling access to disciplinary knowledge, the participants in this study unequivocally indicated that their well-being and access to disciplinary knowledge was a distinct function of the relationships that they had developed with fellow students through the authentic assessment activity. This key finding is presented in the discussion that follows.

\section{COLLEGIALITY, COLLABORATION AND CARING STUDENT LEARNING RELATIONSHIPS AS KEY CATALYST FOR LEARNING}

The social as a space for engendering student well-being clearly emerged as a telling explanation for how students navigated the disciplinary expectation of the programme. Student utterances as to when and how this occurred is presented below.

\section{Accessing the disciplinary discourse through active practice with fellow students}

The participants indicated that collaboration played a significant pedagogical role in acquiring the disciplinary discourse and content in the HSFM101 through an authentic assessment. In the excerpt below, it can be seen that language is a key issue that the student has identified as a barrier to accessing the key concepts of the discipline.

“... English is my second language and we only speak Zulu at home. So understanding these new words in finance and the industry is so new to me and it's a problem to apply this language if you firstly don't know what it means. .."

English was the second language of many participants and their lack of or minimal exposure to finance or the hospitality industry complicated their conceptual understanding of essential disciplinary knowledge. However, through collaborative efforts, the formation of this learning community resulted in the transformation of course content from the tacit to the explicit, enabling the development of disciplinary identity. The assessment design through the scaffolding exercises facilitated a process in which participants had the opportunity to experientially converse in the disciplinary mode. This enabled the students to move the language from abstraction to a condensed and simplified level. This was evident when they were able to read financial and hospitality related transactions.

"... the more we spoke to each other in finance language the better we understood ... what was so difficult to understand is now making more sense ..."

The students added that the assessment tasks encouraged them to interact and network with 
their peers. Such epistemic support improved their learning experience.

"... But working in a group was able to help me a lot. We started learning from each other and some things my friend did not know, I knew, and the other way round, so we could share this and work together to get a better understanding of this world we got ourselves into ..."

The mutual reinforcement of each other's learning and the taking of responsibility for oneself and one's peers learning was a distinct feature of this group of participants. They described each participant as a learning pillar, as they depended on one another's contributions. One participant noted that this assisted in reducing the "jargon" of the language to a simplified level as is also evidenced in the data below.

"Then I go onto the group chat and if anyone asked for help and I got the meaning I was able to assist in whatever way I could. When I meet my group on campus I am happy to report what these words finally mean and we are able to read the transactions as the meanings make better sense now. Then when I explain to my friend I able to understand even better. So I also found that what I learn from someone else I am able to share this information with others that are still in the dark ... BENEFITS ME BIG TIME!!"

Students commented that online engagement facilitated and supported learning, enabling them to find deeper meaning in content, language and context. Students that experienced difficulties in reading and analysing transactions were able to overcome this challenge by sharing or asking for support from one another, a process that led to deeper conceptual understandings of specific disciplinary knowledge.

Collaborative efforts through the use of learning resources such as Blackboard, tutorials, the library, and the group chat offered a range of benefits for many of the participants. Most embraced these resources as useful and novel. Students stated that both virtual and physical learning tools spawned a learning network and sustained continuous engagement. The participants commented that their confidence and enthusiasm in engaging with the assessment and disciplinary knowledge improved.

"At first I had problems getting used to it but later I realized its benefits and I felt in this subject I was ahead of everyone cos it kept me focused and learning for me happened all the time. I so glad to know that from next year that we going to use it in all other subjects. I really felt excited to know that we were going start a new way of learning and communicating through BB."

“... for me using technology was great cos I enjoy being $\mathrm{u}$ to date with new stuff and we never used this in school before so it was great. We were even able to communicate with the lecturer through the WhatsApp."

While this was a new way of learning for many of the participants, they described it as a welcome supplement: 
"For me backboard was first a challenge but once I got to know how to access it, then also the BB helped cos we were given more activities besides the class ones to help us practice and that helped with the project a great deal. ... and the best part was when I used to help my friend with this information as they had no internet and could not access BLACKBOARD."

Thus, the benefits and strengths of BB overshadowed its drawbacks. Virtual classrooms were able to address their areas of concern and they welcomed the feedback received. Similarly, students appreciated the types of activities displayed on BB. They were subsequently able to apply their improved knowledge to the assessment activities with ease and confidence. Some also assisted fellow students that lacked internet access. Collaboration thus motivated the students to learn.

"I would like to say at first I was so afraid when I heard about this word 'Blackboard'. I had never used a computer or did not even know what is 'Wi-Fi'. I realized if I want to pass I have to overcome my fears by taking the first step to learn what this world of technology is all about."

The participants also expressed their appreciation for the support they received in accessing digital tools. This improved their confidence in attempting the assessment activities and the constructive engagement that followed. They overcame their fear of new technology and adopted a more flexible attitude to this learning tool.

"And when my friends helped me to access the journal, and activities, I realized what I could have missed out on ... The assessment activities posted on BB helped a lot and the online discussions were able to get me back on track. I learnt that you can only fail when you never tried."

The students also noted that reflective writing, especially the online journal, created a positive and comfortable learning space. They appreciated the rapport between themselves and the instructor (myself).

"The reflective journal was a great source of help. I am rather a shy and private person and talking to people and expressing my ideas can be a challenge for me. At least when I don't understand something I am able to communicate with my lecturer using the reflective journal, and she was able to help me in many ways. Technology was something new for. But this online journal made it easier for me to communicate and express my ideas. As the project needed us to work in groups and share our ideas. So the online journals also made it easier for me to chat to (the tutor) and also to share my problems and most of the time I got very useful answers. So it's the best way of communicating for me. It was my like having my own little classroom and that I had the teacher all for myself (reflective journals). I was able to ask all the questions that troubled me ..."

Participants reported that this learning forum prompted them to think more openly and 
creatively with no inhibitions or restrictions caused by personality clashes. Some participants stated that reflective journaling enabled them to share their concerns and fears. This reduced the pressure and anxiety of the assessment. Students valued the dialogue and the feedback received thereby encouraging reflective learning. It encouraged them to become more active participants in the writing and reading processes. They added that they were able to revise, defend, and rethink their reflective writing. Such reflection contributed to a better understanding of the disciplinary knowledge.

Moreover, the participants highlighted that collaborating through social media prompted active engagement and effective communication such as updating and notifications on assessment progress.

"Then there was the WhatsApp group chat which kept us up to date with our work and when we wanted to meet or discuss anything we used the WhatsApp. The group chat was very useful for me, as it kept me up to date on what's due, our meeting dates and our different responsibilities that each one had for the project. I managed to get myself a smart phone and was now able to go on the group chat. The class interaction was amazing."

Social media also enabled the students to express and share ideas. They added that by critically reflecting on the dialogue through interactive engagement, the stages of the assessment became meaningful and achievable. This forum also allowed group members to define and assume responsibilities and learn to meet deadlines throughout the various stages of the assessment.

Most of the focus group members appreciated the tutorials. They stated that moving from the large lecture class of 170 students to the smaller group of 20 made an impact on their cognitive development.

"Tutorials were excellent as our numbers were much smaller than in the big class. So here to we had great opportunity to interact with one another and understand better. I found the tutorials to be more helpful, the classroom was a nightmare as I was not used to so many being in a class. But tutorials made my understanding much simpler and easier. I could raise my questions about the project; we also had group activities during tuts which was monitored by the tutor. We enjoyed the vibe at tuts and was more relaxed and got more closer with each other."

They contrasted the formal lecture environment with the vibrant, free and enjoyable tutorial setting. The students added that they learnt more during tutorials, as they were each given the opportunity to reflect, analyse and enquire about content that baffled them. Close interaction in a small group fostered deeper understanding and confidence in undertaking the assessment activities and tasks.

Similarly, students that perceived the assessment tasks as facilitating the integration of 
knowledge claimed an ontological and epistemic shift in their identity. Students found that they were able to make that gradual shift from liminality. ${ }^{1}$ Given, the collaborative nature of authentic learning, students found that the assessment tasks afforded them an opportunity to engage with troublesome knowledge. For example, the scaffolds such as the online reflective tools and activities as well as the tutorial support that the AA design had to offer, promoted opportunities for students to interactively engage and reflect on this engagement. This in turn demonstrated that some of the students, who successfully and critically engaged, fostered the successful mastery of conceptual knowledge.

Having developed their conceptual knowledge students were able to demonstrate their metacognitive skills through critical reflection and peer engagement. Seeing that the internalisation of knowledge was mainly attributable to their perpetual engagement of authentic activities throughout the semester, students relished this path to their epistemic access. The advantage of employing reflective tasks as part of the assessment design not only stimulated the students to recognise their own academic needs but also to take their learning to a much deeper level. In such instances, some students were able to recognise their metacognitive skills merely through observation of their peers, whilst others through the authentic practice of trial and error.

In addition the guidance offered by scaffolds permitted students to complete tasks that posed difficulties. In such cases authentic tools presented evidence of students' reflective and deep thinking skills, indicative of some of the successful academic outcomes achieved. Authentic tasks also enabled students to think about their own thinking, evaluating their own learning strengths and weaknesses.

A notable finding in this study was student's appreciation for maintaining a reflective journal. This tool not only gave them reason to reflect and act on their learning, but more significantly, they valued the regular and valuable feedback. Similarly, the value of feedback served not only as a guidance tool but also assisted in building students' confidence in conceptual understanding of key foundational concepts. Students found feedback and discussion in online learning forums stimulating, engaging and challenging. They subsequently committed to this learning space. The cultivation of such digital spaces as warm, inclusive and safe, permitted students to shed off their previous resistance and fear to engage online. Hence this not only motivated their desire to regularly engage in authentic ways, but also fostered a positive, enabling learning journey. Students started to recognise the value and significance of team work and effective communication that was necessary for the completion of authentic tasks.

Students optimised the cognitive and affective benefits of the small tutorial group's, as 
they found learning to be more relaxed, safer and accommodating. In addition, they also appreciated that such sessions, not only stimulated their personal interest in Finance but also served to support and guide their conceptual understanding and procedural knowledge. Through the process of deliberation and engagement, these collaborative learning spaces enabled students to engage deeply with authentic activities and tasks.

\section{Motivation and a changed attitude}

Most of the participants endorsed the collaborative activities required by the authentic assessment. They remarked that active engagement fostered motivation and changed their views to the subject.

“... Learning new ideas and finding ways to understand this subject (which I dreaded) made me feel motivated and now more excited about this subject. It was great to see how your peers are always there when you most needed them. Our group activities were all done in togetherness and we were able to overcome many of our challenges ..."

From the above data, it is evident that the enabling mechanisms that were triggered by the AA task contributed to enabling students to come to seek out successful ways to acquire the knowledge of the discipline. They concurred that learning from one another and sustaining this new learning community kept them focused and on the right path for the entire semester. Furthermore, they stressed reliance on one another for academic guidance and support. It was noted that their initial fears and anxiety regarding this module were greatly reduced through positive interaction. When they realised that they can depend on others, their confidence and enthusiasm soared.

The participants stated that, when they were first presented with the assessment, they were alarmed at its various tasks and cognitive demands, but working as a group afforded them the identity of team players. In this way, they were able to overcome personality clashes and support one another in order to achieve positive outcomes. They stressed that their synergistic efforts achieved favourable results and that learning together could be exciting.

“... first time I worked in a group. I was so worried when I saw how big the project is and whether I be able to cope. But working in group took care of most my fears. Although we experienced some hiccups in the start, we later realized how much we need other and how much we can learn from each other. In every way the group taught me to be strong and focused and not to lose courage. In the end we ... did fantastic in the project as our group scored a fantastic mark. This was through the combined effort of all the members and most important that learning became fun for us!" 
Since the assessment demanded a range of group activities that called for collaboration, students gained various skills and capabilities. The tasks were designed in a way that integrated such skills and abilities:

"When learnt about BB, and that we have do access online activities and communicate through the reflective journal, I was hopelessly scared! I did not have any technology skills or even used a computer before. This word 'Wi-Fi' AND social media was totally new to me. That [was] when I was forced to buy my own smart phone and try to use all these new tools. I was so surprised with myself as nobody taught me, but I learnt through observation from the members in my group and ... in fact I now know more than them, as they always asking me to sort their phones and access BB THESE DAYS!"

Furthermore, participants reported that some of the skills developed through collaborative exercises benefited them in their everyday lives. Similarly, whilst many stated that they lacked information literacy, they valued the shared learning as it improved their technological skills due to their exposure to e-learning. These scaffolding resources nurtured self-regulated learning and self-efficacy.

In the extract below, one participant reflects on very specific knowledge and skills that she acquired as a result of engaging with the AA task and her confidence in declaring her future aspirations as a potential entrepreneur.

“... a very shy person and on project day, I was shocked at my marketing skills and entrepreneurial skills when I was the one that sold most of the products. My group gave that confidence ... This assessment has brought about more than just good marks ... one day I am going to open my own BUSINESS!"

Another participant proudly reported that she acquired leadership skills due to the group's faith in her. She has previously assumed that this trait was not part of her make-up.

"I was told that I am going to lead the group, first I did not accept, but the members all had faith in me, and I proved them to be right ... and we so organized."

She added that this made her believe in herself.

Furthermore, the collaborative activities enabled the students to critically examine and evaluate one another's strengths and weaknesses, thereby highlighting their fortes and capabilities. They reported that they were able to listen to one another (some admitted that this was their initial weakness).

"As ... the eldest child at home, my problem was that I never listen to others ... but others must listen to me. But this project taught me so much and I mainly learn to listen to others and give 
others a chance ... to become a team player. And in the end their ideas proved to be better than mine as our work was a success in the end ... now use this skill - 'to listen and to learn' in my everyday life and it has changed me as a better person."

Some commented on the value of being a team player, as this is a valuable trait in the hospitality industry. They were also able to critically examine their own progress and understanding that is required to yield positive academic outcomes.

\section{DISCUSSION AND CONCLUDING COMMENTS}

Muller's notion of the nexus between knowledges of practice and theory (Muller 2014) is useful as it explains that knowledge of theory and of practice through the AA task, is what might better enable both the acquisition and use of HFM knowledge. For most of the students the access towards knowing was mainly attributable to the collaborative nature of the authentic tasks. The social constructivist nature of the authentic assessment advocates for students to work collaboratively. The majority of the participants in this study expressed their appreciation of being collectively assessed. For most of them the initial anxieties and tensions they felt at the start of the semester was mainly reduced through the group activities. The shared camaraderie support elevated students confidence; thus increasing their willingness and excitement to learn. Students admitted that they no long longer felt alienated and disengaged from the course as the synergistic benefits of the assessment perpetuated the need to work together as well as independently. Collaborative learning under the guidance of a facilitator can lead students, to deeper learning and thinking and has the ability to develop positive interdependence and individual accountability (Mills 2009, 609-611). Students felt that the group's activities, the tutorials and the reflective engagement built and increased their self-confidence and enabled them to even work independently.

However, students did admit the initial tensions and discomfort they experience when working together, most importantly, when they could not reach consensus during the assessment activities. However, other platforms of collaboration such as the smaller group tutorial sessions as well as the reflective experience, highlighted these negative experiences and was resolved at most times.

Participants appreciated the opinions, views and input of their peers and began to see the value of working harmoniously as a team player. They came to the realisation that a very essential skill and competence required in the hospitality industry, is having the ability to communicate, interact and solve problems not in silos but as a collective team. A growing body of scholarship confirms that by deploying a collaborative learning strategy affords students the opportunity not only to learn better from each other but also to build positive interrelationships 
with each other (Gray et al. 2013, 35-37; Atkins 2010, 235; Thondhlana and Belluigi 2014, 4142).

Fostering collaborative activities not only improved, but developed students' interpersonal skills, teamwork, communication and problem solving skills, but also enhanced their conceptual abilities as it related to disciplinary knowledge acquisition (Benckendorff 2009, 102-104; Bagul and Marzuki 2007, 16-17 and Hwang, Hung and Chen 2014, 130-132). In addition collaboration presented students with opportunities to reflect on what they knew and their own learning a finding that is confirmed by Levin (2004, 9-16) who advocates that working together in groups affords students an academic learning opportunity as they become immersed in the assessment and processing of alien values and ideas and react to unfamiliar "knowledge" territories. Being able to reflect, allowed the students to channel their efforts towards evaluating their current learning. Reflective exercises enabled students to develop metacognitive abilities to think about what they know and need to know, and led to new understandings (Yang and Lim 2016, 1279-1280).

While the benefits of co-operative learning and ICT are well documented, the contribution of this study is significant as it speaks to Muller's critique of the Morrow project (Muller 2014), namely, that Morrow afforded the field a "meta" theory, a useful, but somewhat broad and generic framework from which to proceed. This study demonstrates the potential that a very specific pedagogical practice (AA) might complement and enable access to disciplinary knowledge. An "unexpected" finding was that although AA does not prescribe collaborative learning as preferred technique for teaching and learning, the power of student mutual engagement towards a common objective, namely that of mastering the knowledge and tenets of the discipline, was indeed compelling. This, together with the strategic employment of ICT and an emphasis on reflective writing about learning and learning processes work in concert to create the conditions for students to develop the competences to be successful in the discipline.

\section{CONCLUSION}

In this article we presented an account of how student well-being might be achieved through a carefully planned academic programme that is theoretically informed. In this instance the application of the constructs epistemic access and authentic assessment proved valuable. Authentic assessment that integrates active student engagement with the tasks and with each certainly has much potential to improve students' chances of success especially in high-risk subjects characterised by large student numbers. The (im)practicality of the teacher (lecturer) to access and communicate with each individual student is a reality in the South African higher education context. Learning programmes that facilitate the process of collaboration is an 
effective way of getting students to view each other as powerful resources for learning, to take responsibility for each other's learning. It has the potential to move learning beyond the superficial towards deep conceptual understandings, towards achieving epistemic access to the discourse of the discipline. Enabling epistemic access is a crucial aspect in the process of creating conditions for student academic well-being.

\section{NOTE}

1. Liminality refers to students experiencing difficulty in understanding threshold concepts which may leave them in $\mathrm{n}$ a suspended state of poor or limited understanding (Land, Meyer and Baillie 2010)

\section{REFERENCES}

Antia, Bassey E. and Charlyn Dyers. 2016. Epistemological access through lecture materials in multiple modes and language varieties: The role of ideologies and multilingual literacy practices in student evaluations of such materials at a South African University. Language Policy 15(4): 525-545.

Arbee, A., W. Hugo and C. Thomson. 2014. Epistemological access in Marketing - a demonstration of the use of legitimation code theory in Higher Education. Journal of Education 59: 39-62.

Ashford-Rowe, Kevin, Janice Herrington and Christine Brown. 2014. Establishing the critical elements that determine authentic assessment. Assessment \& Evaluation in Higher Education 39(2): 205222.

Atkins, Anthony T. 2010. Collaborating online: Digital strategies for group work. writingspaces 1: 235.

Bagul, Awangku Hasanal Bahar Pengiran and Kamarul Mizal Marzuki. 2007. Tourism and hospitality education in Universiti Malaysia Sabah (UMS).

Benckendorff, P. 2009. Evaluating wikis as an assessment tool for developing collaboration and knowledge management skills. Journal of Hospitality and Tourism Management 16(1): 102-112.

Boughey, Chrissie and Penny Niven. 2012. The emergence of research in the South African academic development movement. Higher Education Research \& Development 31(5): 641-653.

Boughey, Chrissie and Sioux McKenna. 2016. Academic literacy and the decontextualised learner. Critical Studies in Teaching and Learning 4(2): 1-9.

Boughey, Chrissie. 2005. "Epistemological" access to the university: An alternative perspective. South African Journal of Higher Education 19(3): 230-242.

Charmaz, Kathy. 2006. Constructing grounded theory: A practical guide through qualitative research. Sage Publications Ltd., London.

CHE see Council on Higher Education.

Council on Higher Education. 2013. A proposal for undergraduate curriculum reform in South Africa: The case for a flexible curriculum structure. Report of the Task Team on Undergraduate Curriculum Structure.

Egalite, Anna J. 2016. How family background influences student achievement. Education Next 16(2).

Ellery, Karen. 2017. Conceptualising knowledge for access in the sciences: Academic development from a social realist perspective. Higher Education 74(5): 915-931.

Etikan, Ilker, Sulaiman Abubakar Musa, and Rukayya Sunusi Alkassim. 2016. Comparison of convenience sampling and purposive sampling. American Journal of Theoretical and Applied Statistics 5(1): 1-4.

Ferreira, Ana and Belinda Mendelowitz. 2009. Diversity, double-talk and (mis) alignment: Pedagogic moves for epistemological access. Southern African Linguistics and Applied Language Studies 
27(1): 77-92.

Furlong, Andy. 2009. Revisiting transitional metaphors: Reproducing social inequalities under the conditions of late modernity. Journal of Education and Work 22(5): 343-353.

Gamede, Thobekile. 2005. The biography of "access" as an expression of human rights in South African education policies. PhD dissertation, University of Pretoria.

Goh, Edmund and Madalyn Scerri. 2016. "I study sccounting because I have to": An exploratory study of hospitality students' attitudes toward accounting education. Journal of Hospitality \& Tourism Education 28(2): 85-94.

Heleta, S. 2016. Decolonisation of higher education: Dismantling epistemic violence and Eurocentrism in South Africa. Transformation in Higher Education 1(1): 1-8.

Herrington, Jan and Ron Oliver. 2000. An instructional design framework for authentic learning environments. Educational Technology Research and Development 48(3): 23-48.

Hornsby, David J. and Ruksana Osman. 2014. Massification in higher education: Large classes and student learning. Higher Education 67(6): 711-719.

James, Lincoln Then and Riza Cassidy. 2018. Authentic assessment in business education: Its effects on student satisfaction and promoting behaviour. Studies in Higher Education 43(3): 401-415.

Gray, Brendan, Sarah Stein, Phil Osborne and Robert Aitken. 2013. Collaborative learning in a strategy education context. Practice and Evidence of the Scholarship of Teaching and Learning in Higher Education 8(1): 35-55.

Human-Vogel, Salome and Peter Patrick Mahlangu. 2009. Commitment in academic contexts: First year education students' beliefs about the aspects of self, the lecturer and instruction. South African Journal of Higher Education 23(2): 309-328.

Human-Vogel, Salomé. 2006. Students' mental models of positive mood and self-regulation in learning. South African Journal of Psychology 36(3): 613-633.

Hwang, G. J., C. M. Hung and N. S. Chen. 2014. Improving learning achievements, motivations and problem-solving skills through a peer assessment-based game development approach. Educational Technology Research and Development 62(2): 129-145.

Jacobs, Cecilia. 2007. Towards a critical understanding of the teaching of discipline-specific academic literacies: Making the tacit explicit. Journal of Education 41(1): 59-81.

Kotta, Linda Thokozile. 2006. Affording or constraining epistemological access: An analysis of a casebased approach in a first year process and materials engineering course. $\mathrm{PhD}$ dissertation.

Land, Ray, Jan H. F. Meyer and Caroline Baillie. (Eds.). 2010. Threshold concepts and transformational learning. Rotterdam: Sense Publishers.

Lange, Lis. 2017. 20 Years of higher education curriculum policy in South Africa. Journal of Education (University of KwaZulu-Natal) 68: 31-57.

Layton, Delia and Sioux McKenna. 2016. Partnerships and parents-relationships in tutorial programmes. Higher Education Research \& Development 35(2): 296-308.

Levin, Peter. 2004. Successful teamwork! McGraw-Hill Education (UK).

Liccardo, Sabrina, Hannah Botsis and Yasmine Dominguez-Whitehead. 2015. Background knowledge and epistemological access: Challenges facing black women in a set scholarship programme: Part 2. South African Journal of Higher Education 29(1): 373-389.

Lotz-Sisitka, Heila. 2009. Epistemological access as an open question in education. Journal of Education 46: 57-79.

Mampane, Ruth and Cecilia Bouwer. 2011. The influence of township schools on the resilience of their learners. South African Journal of Education 31(1): 114-126.

Maphosa, C., T. D. Sikhwari, C. Ndebele and M. Masehela. 2014. Interrogating factors affecting students' epistemological access in a South African university. The Anthropologist 17(2): 409420. 
Mgqwashu, E. M. 2007. English studies and language teaching: Language acquisition and discursive critique.

Mills, Nicole. 2009. A guide du Routard simulation: Increasing self-efficacy in the stand ards through project-based learning. Foreign Language Annals 42(4): 607-639.

Mingo, Wendye Dianne. 2013. The effects of applying authentic learning strategies to develop computational thinking skills in computer literacy students.

Mollett, Jean and Ann Cameron. 2016. Making a case for epistemological access in biotechnology education in Southern Africa. African Journal of Research in Mathematics, Science and Technology Education 20(3): 234-243.

Morrow, Wally. 2009. Bounds of democracy: Epistemological access in higher education.

Muller, Johan. 2014. Every picture tells a story: Epistemological access and knowledge. Education as Change 18(2): 255-269.

Nkonki, Vuyisile and Siyanda Ntlabathi. 2014. An evaluation of foundation provisioning curriculum delivery workshops for enabling epistemological access. Mediterranean Journal of Social Sciences 5(11): 109.

Northcutt, Norvell and Danny McCoy. 2004. Interactive qualitative analysis: A systems method for qualitative research. Sage.

Rabiee, Fatemeh. 2004. Focus-group interview and data analysis. Proceedings of the Nutrition Society 63(4): 655-660.

Rusznyak, L., L. Dison, M. Moosa and M. Poo. 2017. Supporting the academic success of first-year students: A study of the epistemological access they acquired through a lecture and text. South African Journal of Higher Education 31(1): 207-226.

Scott, Ian, Nanette Yeld and Jane Hendry. (Eds.). 2007. Higher education monitor: A case for improving teaching and learning in South African higher education. Pretoria: Council on Higher Education.

Scott, Ian. 2009. Academic development in South African higher education. Higher education in South Africa: A scholarly look behind the scenes, 21-47.

Sharma, G., 2017. Pros and cons of different sampling techniques. International Journal of Applied Research 3(7): 749-752.

Slonimsky, Yael. 2006. Pedagogic responsiveness for academic depth. Journal of Education 40(1): 3758.

Snowball, J. D. and S. McKenna. 2017. Student-generated content: An approach to harnessing the power of diversity in higher education. Teaching in Higher Education 22(5): 604-618.

Spaull, Nic. 2015. Schooling in South Africa: How low-quality education becomes a poverty trap. South African Child Gauge 12: 34-41.

Stanton-Salazar, Ricardo. 1997. A social capital framework for understanding the socialization of racial minority children and youths. Harvard Educational Review 67(1): 1-41.

Strayhorn, Terrell L. 2010. When race and gender collide: Social and cultural capital's influence on the academic achievement of African American and Latino males. The Review of Higher Education 33(3): 307-332.

Tabane, Ramodungoane James. 2010. Integration and learners' feelings of belonging in a desegregated former House of Delegates school. PhD dissertation. University of Pretoria.

Thondhlana, Gladman and Dina Zoe Belluigi. 2014. Group work as "terrains of learning" for students in South African higher education. Perspectives in Education 32(4): 40-55.

Tierney, William G. and Linda Serra Hagedorn. (Eds.). 2002. Increasing access to college: Extending possibilities for all students. SUNY Press.

Van Zyl, André. 2013. Teaching the students we have: Two perspectives on first year students at the University of Johannesburg and the UJ first year experience initiative.

Vorster, Jo-Anne and Lynn Quinn. 2017. The "decolonial turn": What does it mean for academic staff 
development? Education as Change 21(1): 31-49.

$\mathrm{Vu}$, Thuy T. and Gloria Dall'Alba. 2014. Authentic assessment for student learning: An ontological conceptualisation. Educational Philosophy and Theory 46(7): 778-791.

Waglay, Afsar Ali. 2013. Exploring the tension between the discourses of affirmative action and the knowledge economy. PhD dissertation. Stellenbosch: Stellenbosch University.

Warburton, Edward C., Rosio Bugarin and Anne-Marie Nunez. 2001. Bridging the gap: Academic preparation and postsecondary success of first-generation students. Statistical Analysis Report. Postsecondary Education Descriptive Analysis Reports.

Yang, Min, Mui Tai and Cher Ping Lim. 2016. The role of e-portfolios in supporting productive learning. British Journal of Educational Technology 47(6): 1276-1286.

Yin, Robert K. 2011. Qualitative research from start to finish. New York, NY: The Guilford. 